\title{
Effects of Reaction Conditions on the Morphology and Property of Sb Doped $\mathrm{SnO}_{2}$ Nanorods Anode
}

\author{
Li Xu ${ }^{1,2, *}$, Huiying Duan ${ }^{1,2}$, Ye Wang ${ }^{1,2}$, Yuefei Lian ${ }^{1,2}$ \\ ${ }^{1}$ School of Chemical Engineering and Technology, Tianjin University, Tianjin 300072, P. R. China \\ ${ }^{2}$ Tianjin Key Laboratory of Membrane Science and Desalination Technology, Tianjin 300072, P. R. \\ China \\ *E-mail: xuli620@163.com
}

doi: $10.20964 / 2018.03 .53$

Received: 19 November 2017 / Accepted: 12 January 2018 / Published: 5 February 2018

\begin{abstract}
Sb-doped $\mathrm{SnO}_{2}$ nanorods anodes were synthesized by a hydrothermal method with $\mathrm{Ti}$ sheets as substrates ( $\mathrm{Ti} / \mathrm{SnO}_{2}-\mathrm{Sb}$-NRs anodes). In this paper, we focus on the effects various preparing conditions, such as the acidity and basicity of the solution, precursor solvent, concentration, reaction temperature, growth time and annealing temperature, on the formation and electrochemical properties of $\mathrm{SnO}_{2}-\mathrm{Sb}$-NRs anodes. The surface morphology of $\mathrm{SnO}_{2}-\mathrm{Sb}$-NRs is investigated by scanning electron microscopy (SEM), and chronoamperometry (CA) is measured as an indirect assessment of the electrochemical performance of the anodes. It is shown that $\mathrm{SnO}_{2}-\mathrm{Sb}$-NRs can be synthesized in both strong acid solution and strong alkaline solution, and the microstructure of Sb-doped $\mathrm{SnO}_{2}$ can be controlled to some extent by varying the reaction conditions. The $\mathrm{Ti} / \mathrm{SnO}_{2}-\mathrm{Sb}-\mathrm{NRs}$ anode shows the best morphology and properties when the precursor concentration is $0.010 \mathrm{~mol} \cdot \mathrm{L}^{-1}$, using ethanolwater $(1: 1, \mathrm{v} / \mathrm{v})$ as the solvent, at $200{ }^{\circ} \mathrm{C}$ for $24 \mathrm{~h}$, and annealing at $550{ }^{\circ} \mathrm{C}$ for $2 \mathrm{~h}$. An electrochemical degradation experiment of Acid Red 73 (AR 73) verifies its good electro-catalytic performance. Moreover, the growth mechanism of the $\mathrm{SnO}_{2}$-Sb-NRs is also discussed.
\end{abstract}

Keywords: Sb-doped $\mathrm{SnO}_{2}$; Nanorods; Hydrothermal; Electrochemical oxidation; Optimal conditions.

\section{FULL TEXT}

(C) 2018 The Authors. Published by ESG (www.electrochemsci.org). This article is an open access article distributed under the terms and conditions of the Creative Commons Attribution license (http://creativecommons.org/licenses/by/4.0/). 